\title{
PEEK VERSUS METALLIC FRAMEWORK FOR EXTRACORONAL ATTACHMENT MANDIBULAR BILATERAL DISTALLY EXTENDED REMOVABLE DENTAL PROSTHESIS (RDP) EVALUATION OF ABUTMENTS BONE HEIGHT CHANGES AND PATIENT SATISFACTION. A RANDOMIZED CLINICAL TRIAL
}

\author{
Nourhan Ahmed Ragheb* and Mohamed Elgamal**
}

\begin{abstract}
Purpose: to evaluate bone height changes around distal abutments (canines) with two different framework materials for extracoronal attachment mandibular bilateral distally extended removable dental prosthesis (RDP) and compare patient satisfaction .

Materials and methods: Twenty-eight mandibular Kennedy class I partially edentulous patients with remaining 6 anterior teeth were selected. For all patients splinting of remaining anterior abutments by porcelain fused to metal crowns, the RDP frameworks were designed by CAD and printed into 3-D resin pattern. The patients were randomly divided into two groups. Patients in group I received extracoronal attachment RDP framework fabricated from milled BioHPP PEEK while patients in group II received extracoronal attachment RDP framework fabricated from Cobalt -Chromium (Co-Cr) material. Digital radiography was used for vertical bone loss (VBL) assessment around canines at insertion, 6 and 12 months. Patient satisfaction was measured after 6 months using visual analog scale (VAS). Statistical analysis was done by t-test and Mann-Whitney.
\end{abstract}

Results: VBL significantly increased from T6 to T12 for both groups where ( $\mathrm{p}=0.038$ and 0.021$)$ for PEEK and Co-Cr framework respectively. there was a significant difference in VBL between two groups at T12 only $(\mathrm{p}=0.012)$ where Co-Cr framework recorded significant higher VBL at T12 than PEEK. As for patients satisfaction, patients who received PEEK RDP frameworks were more satisfied as regards esthetic and comfort than patients who received Co-Cr RDP frameworks

Conclusion: Extracoronal attachment RDPs with PEEK frameworks showed less VBL than those with Co-Cr frameworks. Patients with PEEK frameworks were more satisfied than patients with $\mathrm{Co}-\mathrm{Cr}$ frameworks as regards appearance, comfort, and overall satisfaction.

KEYWORD: Framework materials, Patient satisfaction, PEEK, Bone changes.

* Lecturer, Prosthodontist, Department of Prosthodontics, Faculty of Oral \& Dental Medicine, Kafr El-Shiekh University, Kafr El-Shiekh, Egypt.

** Lecturer, Prosthodontist, Department of Prosthodontics, Faculty of Dentistry, Mansoura University, Eldakahlia, Egypt. 


\section{INTRODUCTION}

Rehabilitation of partially edentulous patients can be decided by a broad variety of prosthetic treatment choices. Relying on demands and clinical needs, restoration of missing teeth can be accomplished by using a simple conventional Removable dental prosthesis (RDP) conventional overdenture, fixed partial denture or dental implants prosthodontics ${ }^{1}$.

In cases of remaining six front teeth, long span distally extended ridges are considered to be a dilemma to both patient and prosthodontist. This is due to lack of a posterior natural tooth to retain a fixed prosthesis. An implant-retained prosthesis is not always likely as a treatment choice due to insufficient bone volume or due to economic reasons ${ }^{2}$.

One of the reasonable non-invasive solutions for rehabilitation of these cases is conventional $\mathrm{RDP}^{3-5}$ some of which may be associated with ridge resorption ${ }^{1}$ and tilting of abutment due to rotational movement throughout three fulcrum axes under functional loading ${ }^{6}$. In addition, the esthetic problem linked with using clasps specifically in the anterior area ${ }^{7}$.

An alternate reconstructive choice that satisfies the aesthetic and functional demands of the patient is a combination of fixed and RDPs attached with attachments ${ }^{8}$. An attachment-retained RDP is considered as an unconventional treatment option of partial edentulism ${ }^{9}$. A semi-precision extra-coronal attachment used with cast metal cobalt chromium alloy (Co-Cr) framework can play marvelous roles in improving both esthetics and retention and consequently raising the patient's personalconfidence ${ }^{10-12}$.

For improving the clinical success in cases rehabilitated by extracoronal semi-precision attachment $\mathrm{RDP}$, it is advocated to include the remaining natural abutment teeth by splinting aiming to remove the harmful effects of extreme abutments loading ${ }^{13,14}$. As well as, designing passively retained extracoronal precision attachment RDP by selecting a suitable type of resilient attachment. Moreover, suitable selection of denture material is important as it has significant influence on bone reduction level throughout the terminal abutments as reported by Wöstmann et al $2005^{15}$.

One of the newly introduced denture base materials in dentistry is the polyether ether ketone (PEEK) which is white, radiolucent in $\mathrm{x}$ ray, and with Young's (elastic) modulus and tensile characteristics that are close to human bone, enamel and dentin with high thermal stability It is not allergic with low plaque attraction ${ }^{16}$. It is not allergic with low plaque attraction ${ }^{17}$. It has a unique chemical structure, which shows stable chemical and physical properties with low water solubility and absorption ${ }^{18}$.

This newly introduced BioHPP PEEK which is a high-performance polymer material in the dental field can be an alternative non-metallic material for RDP framework construction ${ }^{19,20}$. Limited studies used PEEK as an RDP framework material, however they showed the applicability of PEEK material in dentistry offering the patient a metal-free restoration with excellent mechanical properties ${ }^{21-24}$.

Digital solutions using CAD- CAM technology, high accurate 3D scanners and printers are predicted to enhance esthetics, the fit and functional components of RDPs and allow the use of new materials which would not be applied for RDP fabrication, except digitally. PEEK is specially considered because of their desirable characteristics and simplicity of construction. ${ }^{25}$

Patient satisfaction with the prosthesis can have a deep impact on the treatment success as dissatisfaction with an RDP will possibly result in disuse and consequent rehabilitation inability ${ }^{26}$. The satisfaction with the dental prosthesis is multifactorial, involving technical and patient associated variables. Masticatory capability, comfort, retention, phonetics and aesthetics appear 
to be the main factors for satisfaction with the prosthetic appliance ${ }^{26,27}$.

According to the knowledge of the authors, there were limited studies in the dental literature about PEEK frameworks with extra coronal attachments. In addition, current studies need to focus more on patient relevant outcomes.

Hence, the aim of this study was to evaluate the effect of PEEK and Co-Cr as framework material for extracoronal attachment retained RDP on bone height changes to distal abutments as well as patient satisfaction.

The research question for this study "Is the PEEK framework material better than $\mathrm{Co}-\mathrm{Cr}$ framework material for extra coronal attachment RDP regarding bone height changes to distal abutments and patient satisfaction?". SO, the hypothesis of this study is that PEEK is better than Co-Cr as a framework material in RDPs retained by extra coronal attachments as regards bone preservation and patient satisfaction.

\section{MATERIALS AND METHODS}

\section{I-Patient selection}

For the present study, the patients were selected from the outpatient clinic, Prosthodontic Department, Faculty of Dentistry, Kafr El_Sheikh University.

\section{Sample size}

Sample size was calculated according to the clinical findings in another parallel randomized clinical trials (Fayyad and \& Nassouhy, 2017) ${ }^{28}$. In which the authors after 12 months follow up found a significant difference in bone height changes between two different types of RDP prostheses. Alpha significance $=0.05$, and the $80 \%$ power of the study was used. The calculated sample size per group was 12 patients and $15 \%$ to compensate for drop outs, then 14 patients per group, so total number of patients was 28 patients.
All patients had the following inclusion criteria: - Age ranging from 50 to 65 years. Completely edentulous maxillary arch opposed by partially edentulous mandible with only mandibular anterior teeth. They were free from any systemic diseases, had Angle class I maxillomandibular skeletal relation, the distal extension ridge was well formed and covered by healthy, firm mucosa, abutments had healthy periodontal ligament and appropriate crown/root ratio (CRR) as verified by periapical radiographs.

The exclusion criteria included: patients with any systemic disease that could affect the rate of bone resorption, which was confirmed by obtaining a through medical history, patients with parafunctional habits (bruxism and clenching), patients with any septic foci or impacted teeth as proved by panoramic radiograph, as well as patients with tilted or rotated abutments or soft tissue undercuts in areas that will be involved in the RDP design.

\section{For every patient the following procedures were done}

Diagnostic digital panoramic X-ray was done, followed by diagnostic long cone standard digital peri-apical radiographs for the mandibular anterior teeth to define crown /root ratio. Scaling and/or root planning for the remaining mandibular anterior teeth was done, and follow up of oral hygiene measures was carried out for one month to ensure patient's compliance to oral hygiene measures before starting the treatment. Correction of uneven occlusal plane was done either by enameloplasty for over erupted ones or restoration by adding composite for infra erupted one if required.

All selected patients in the present study were informed about all procedures that would be done and the need for frequent recalls and their approvals were obtained. The study was approved by ethical committee in Faculty of Dentistry, Kafr El_Sheikh University, Egypt with number $(\mathrm{KD} / 12 / 21)$. The study protocol was registered on the Clinical Trial website (ClinicalTrials.gov) with identifier: NCT04990453 
Patients were randomly allocated into 2 groups using random generated numbers in Excel spread sheet. The randomization and allocation were made to balance patients' characters (age, sex, bone height of mandibular canines) between groups at base line without significant difference. Group I: in which patients received extracoronal precision attachment RDP frameworks fabricated from PEEK material using milling machine (CAD/CAM technology). Group II: in which patients received extracoronal precision attachment RDP frameworks fabricated from $\mathrm{Co}-\mathrm{Cr}$ material using casting machine.

\section{Prosthetic procedures:}

For each patient, the definitive mandibular extra coronal attachment RDP was designed by using CAD/CAM technology and made according to the following steps: maxillary and mandibular primary impressions were recorded by using irreversible hydrocolloid impressions (C A 37 Superior Pink, Cavex, Holland bv) and poured in dental stone (Dental stone, Super-cal IV, COE laboratories Inc., USA). The mandibular partially edentulous study cast was then secured on the scanner table and scanned by using extra oral 3D scanner (3D scanner, Ceramill map400, Amann Girrbach, Koblach, Austria) to get a virtual model which was digitally surveyed to detect areas of undercut present on the patient's soft tissue, and define the necessary mouth preparation required to obtain vertical path of insertion.

Construction of porcelain fused to metal splinted crowns with patrix attachment: where intraoral abutments preparation of the remaining six anterior teeth was made with a $6^{\circ}$ taper and a in the form of chamfer finish line on the remaining six anterior teeth; after completing the crown reduction a $6^{\circ}$ taper has been founded. In the lab, the crowns were waxed, OT-strategy standard male with 1.8 mm stud (Rhein 83, Italy, Ref. 154PCS) were aligned within distal surface of waxed crowns with parallelometer key (Rhein 83, Italy, Ref. 75AC04).
The male part (patrix) was attached parallel to the path of insertion, over the center of the ridge and near as possible to the preparation. A step was cut in the lingual surface of the waxed-up crowns to house the lingual plate. The shoulders cervical milled ledges were placed approximately $1 \mathrm{~mm}$ above the gingival margin and located at right angles to the path of insertion. Afterwards, the crowns were casted and fitted to the model. Finally try-in was performed in the patient mouth.

A mandibular impression custom tray (Self cured acrylic resin, Acrostone, Dental Factory, Egypt) was constructed on the primary cast. The porcelain crowns were positioned on to the abutment teeth. The custom tray was border molded by using green stick compound (Kerr, Kerr U.K. limited, Netherlands) and secondary impression was made by means of rubber base impression material (orsnwash L zetal plus impression material, zermack SpA, Italy) and poured to get mandibular master cast. Before scanning Strategy plastic caps with stainless/steel housings (Rhein 83, Italy, Ref. 045CSM AY) were included in the patrices of the extracoronal attachments.

\section{Scanning the Master Model}

The mandibular master cast with the porcelain crowns and plastic caps in their housings were placed in position over the attachment patrices then a layer of pink wax was added over the metal housing and adjusted to provide a space in the frameworks fitting surfaces to facilitate the direct pick up procedures by using self-cure acrylic resin. All these components were fixed on the scanner table of the 3D Shape scanning machine dental system to be scanned and get the standard triangulation file (STL) format. This was done after spraying the ridge and the porcelain crowns of the master model by scan-able spray (Telescan Spray zur vorbereitong von oberflacohen. Teleskop kronen). Blue LED and multi-line scanning to capture 140000 points on the surface of the master model to form point cloud. 
A 3D virtual model was created by linking these points cloud with triangular facets. Finally, the 3D virtual model was transferred as STL file format to be ready for wax design of the extra coronal attachment RDPs frameworks using CAD technology.

Digital process and CAD Design of extracoronal attachment RDP Frameworks: Surveying of the virtual master cast was made digitally according to the programmed path of insertion; all unwanted undercuts were then blocked out. Relief was made by selecting the STL data of the mesh-retainer part and lifted $0.5 \mathrm{~mm}$ in an occlusal direction and $0.5 \mathrm{~mm}$ relief is was also specified under the part of lingual plate on the soft tissue side. All components of the framework were chosen from the menu and placed digitally on the modified virtual master cast in the correct position. The symmetrical design of the mandibular RDP frameworks were involved; lingual plate major connectors joining 2- distal extension denture bases with external finish line, the entire framework design was virtually verified from all surfaces (Fig. 1:A\&B).

STL file of the virtual framework was accustomed to print the resin pattern (Castable Blend 3D Resin, Fun To Do Co, Alkmaar, The Netherlands ) by using 3D printer which was tested on the master cast before intraoral try in. Intraoral try in was performed to verify all the framework components (Fig. 2) and define any needed corrections that would be done on the STL file.

\section{Framework construction:}

For (group I) extracoronal attachment RDP with PEEK framework was constructed as follows: The virtual 3D framework (STL) file was referred to the milling machine (Ceramill Motion 2, Amann Girrbach) to start the milling process of PEEK discs (BioHPP, bredent GmbH \& Co.KG, Senden, Germany) to construct mandibular extracoronal attachment RDP PEEK framework (Fig. 3). The PEEK framework was next finished and polished then reseated on the master cast to test its fitting. Next, the PEEK framework was tried in the patient mouth to test its fitting (Fig. 4:A\&B).

\section{For (group II) extracoronal attachment RPD with metallic (Co-Cr) framework construction was done as follow}

The virtual 3D framework (STL) file with supporting bars and sprues was printed with resin and afterward invested, burnt out, and lastly casted with $\mathrm{Co}-\mathrm{Cr}$ alloy (Ticonium, Prenium 100, Ticonium Co., New York USA) to construct mandibular attachment RDP metallic framework. The metallic framework was subsequently finished, polished and relocated on the master cast to test its adaptation. Next, the metallic framework was tried in the patient mouth to verify its fitting.



Fig. (1) (A) Digital preparation of the virtual model of master cast. (B) Digital designing of the virtual framework. 


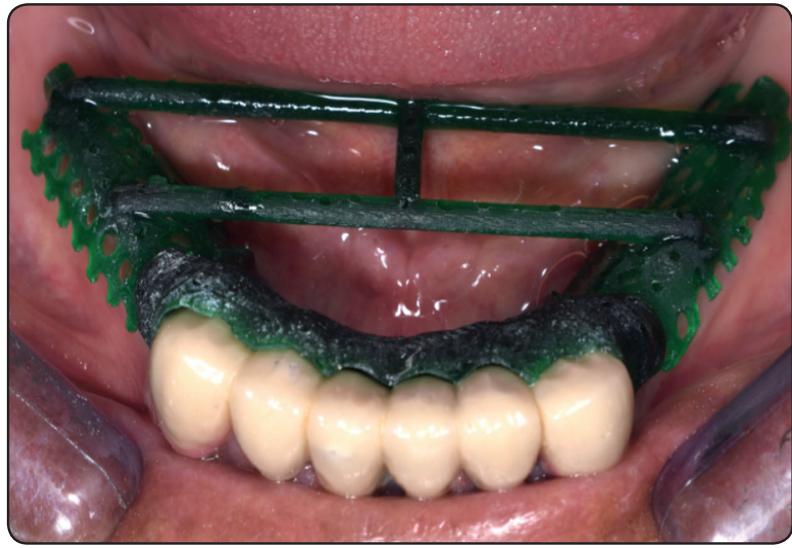

Fig. (2): Intra oral try in of 3D printed resin pattern of the framework.

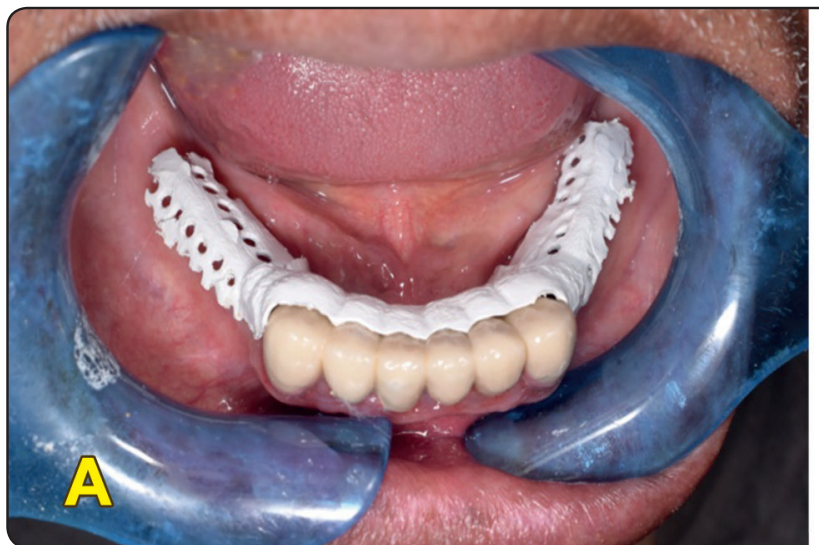

Fig. (4) (A, B): Frontal and lingual view of intra-oral PEEK framewrork try in for group (I)

\section{For each patient the in both groups:}

Maxillary secondary impressions were made using zinc oxide-Eugenol-free impression material (Cavex impression paste, Holland bv) in border molded (green molding compound, Xantygen, Bayer Co. Lever Kusen) auto polymerized resin special trays. Impressions were then poured in hard dental stone.

\section{Altered cast impression technique was made} by the following: the interfering undercuts in the saddle area of the anatomical master cast were blocked out and a separating medium was applied. For PEEK and metallic RDPs after framework was completely seated on the cast, autopolymerized acrylic resin was adapted to the stratus of minor connector to ensure that it was mechanically
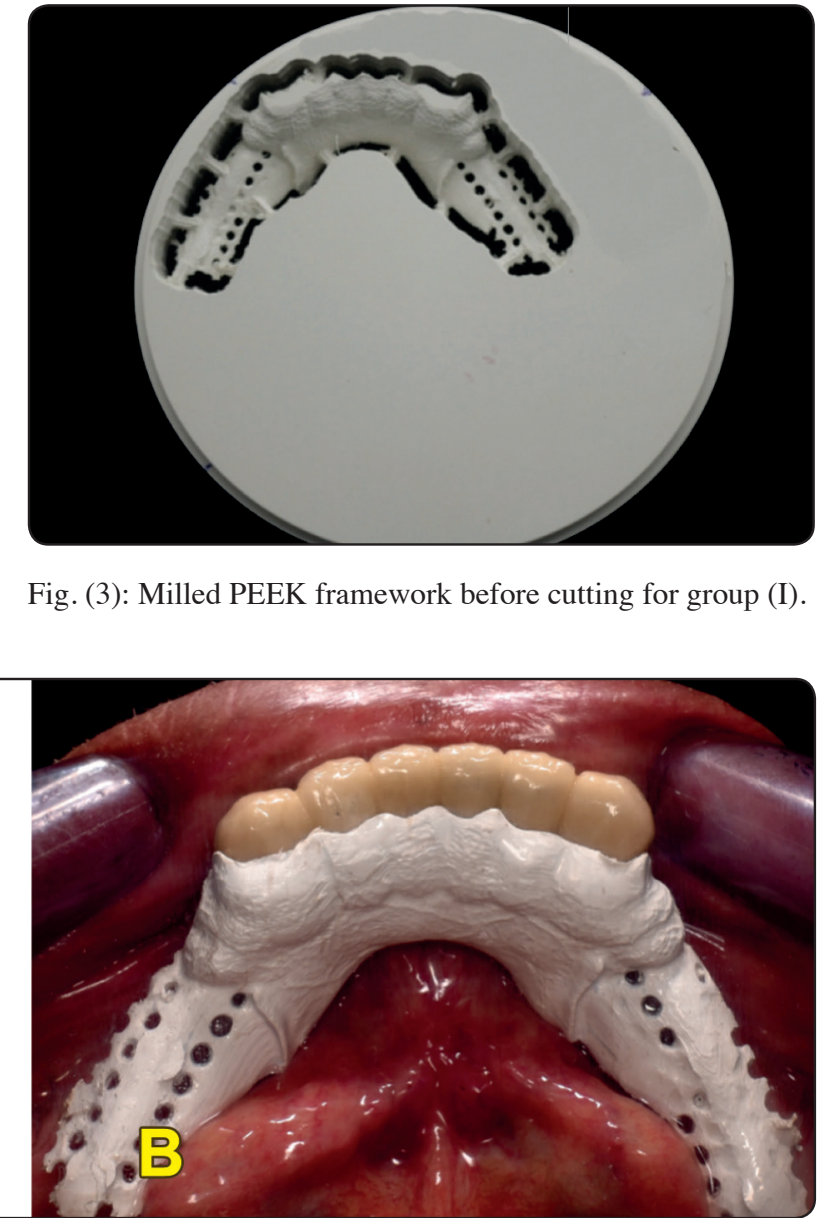

Fig. (3): Milled PEEK framework before cutting for group (I).

retained in its place. The borders were trimmed to be gently rounded. Impressions of the distal extension areas was made using zinc oxideeugenol (ZOE) impression material in a border molded special tray. Adjustment of the master cast for altered cast was carried out by drawing a line around the saddle areas, and subsequently sawing the cast at this line to remove the saddle areas from the master cast. Assembly of the framework and impression was appropriately sealed and seated on the modified master cast, boxing procedure was done for this assembly. Stone was then mixed and poured to produce the altered cast.

Record blocks were made on the maxillary secondary cast and the mandibular framework on the altered master cast. Following registration of the jaw relation, the casts was attached on 
semi-adjustable articulator (Dentatus international, Arts, Hagersten, Sweeden) using maxillary face bow (AB Dentatus, Stockholm) for attaching maxillary cast and centric relation record for mandibular one. Bilateral balanced occlusal scheme by using semianatomic acrylic teeth (Vitapan ${ }^{\circledR}$, Vita Zahnfabrik, Bad Säckingen, Germany) was done. Try-in was carried out in the patient's mouth, then the denture was processed (Heat cured acrylic resin, Acrostone Dental Factory, Egypt), finished and polished. Finally, the occlusion was adjusted.

\section{Direct Pick-Up Technique for Either PEEK or Co-Cr Frameworks}

All crowns were cemented by using resin luting cement (GC Fuji PLUSVita ${ }^{\circledR}$-Zahnfabrik Bad Säckingen, Germany). Direct pick up was performed after cementaion of crowns according to the following procedures: the strategy cap inserting tool (Rhein 83, Italy, Ref. 486ICS) was used to insert and push the cap with friction in its place in metal housing (orange plastic cap for light snap in friction was the preferred matrix). Then the metal housing including the female part was placed on the male part intraorally. The spaced fitting surface of the RDP corresponding to the area of the attachment was filled with self-cured acrylic resin. The patient was asked to bite in centric position and left to cure to pick up the female part Fig.5 (A, B\&C); Fig 6 (A, $\mathbf{B \& C}$ ). The RDP was refitted in the patient's mouth and checked for stability, retention, extension, and occlusion.

Periapical radiographs of distal abutments (canines) were made at the time of insertion (T0) and 6 (T6) and 12 months (T12) later. Patient satisfaction was tested after six months follow up period.

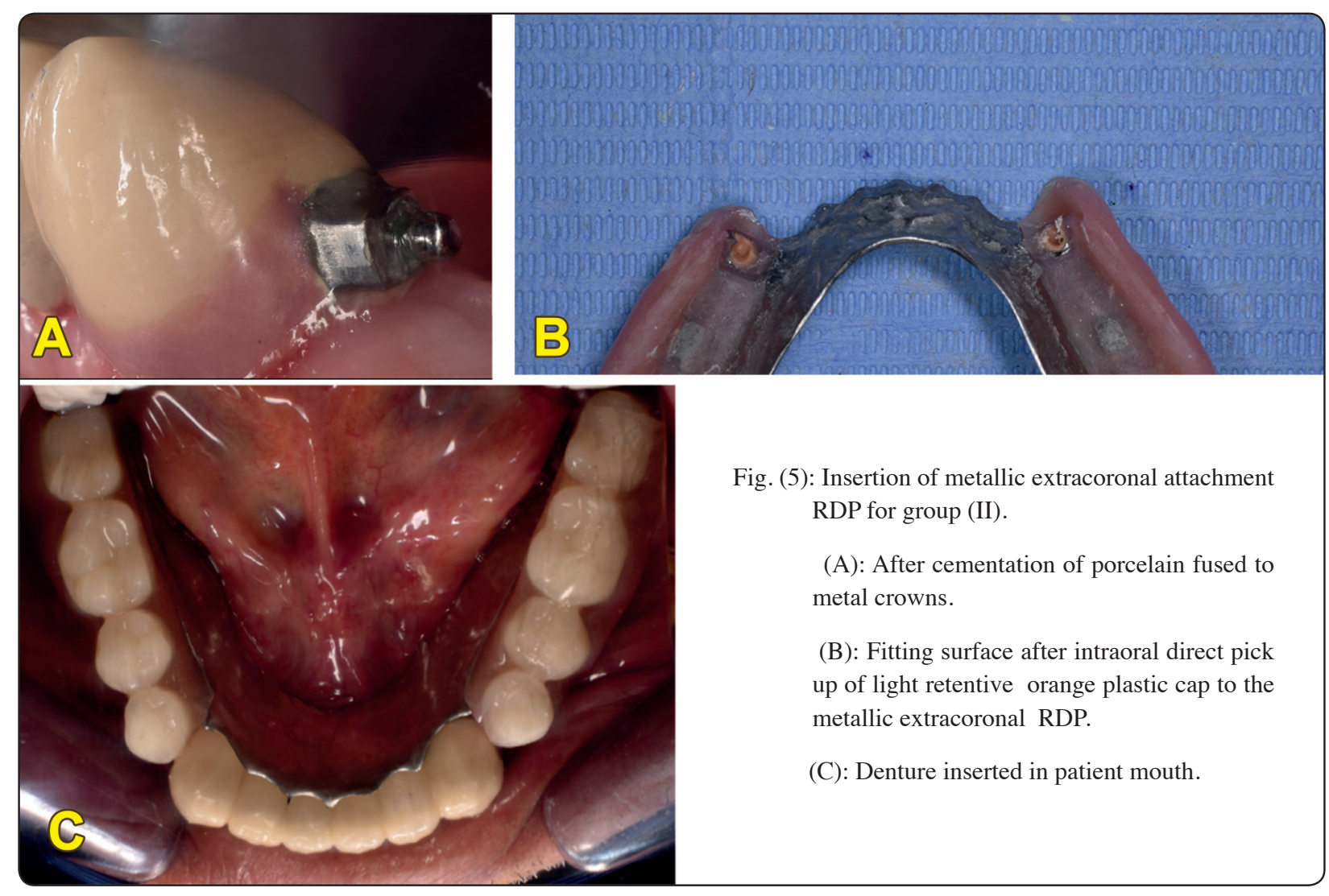



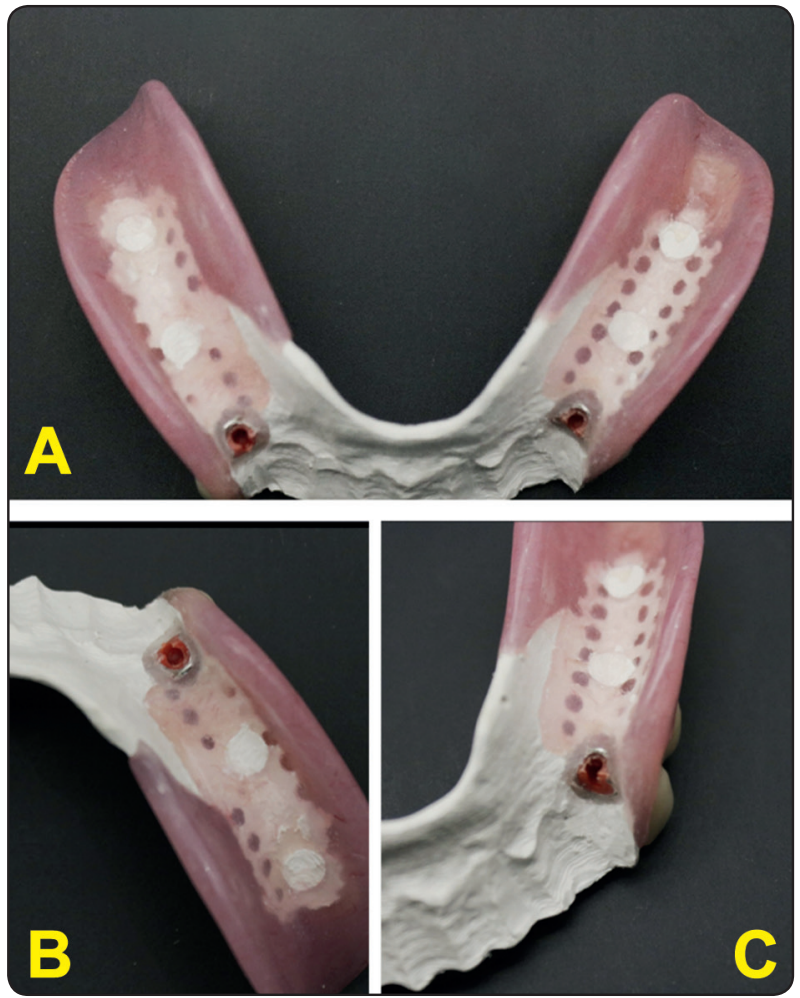

Fig. (6) (A, B\& C): Fitting surface after intraoral direct pick up of light retentive orange plastic cap to the PEEK extracoronal RDP.

\section{III- Evaluation Methods}

\section{I-Radiographic Evaluation}

An image plate was attached on a radiographic stent specially constructed for each patient to make a standardized periapical radiograph for the abutments by using the Dentsply/rinn XCP tools (long, round BID cone paralleling technique) according to (Langland et al, 2002) ${ }^{29}$ :

- Direct digital radiography using the dental X-ray unit $\left(\right.$ Xgenus ${ }^{\circledR}$, de Gotzen ${ }^{\circledR}$ S.r.l., Roma, Italy) set up at $70 \mathrm{kVp}$ and $8 \mathrm{~mA}$ for making intra-oral digital radiographic images by using the software of the imaging system (Scanoralite Version. 3.2.6). The digital images were shown on a computer screen and the standardization of brightness and contrast of all images was done. The radiographic image was made at the time of insertion, six months and twelve months later (at the end of the study). The stored images of each single patient were interpreted at the end of the follow up period.

\section{Image analysis}

The linear measurement system contributed by the special software of the Scanoralite was used for measuring the mesial and distal marginal bone height around the canine abutments bilaterally in both groups. Fig (7)

- Stud dimensions of extracoronal attachment in the radiographs were compared with actual stud dimensions to identify magnification errors.

- Regarding to vertical alveolar bone changes around canine abutments, dimensions were made as follow: the distance between cementoenamel junction (A point) and first bone to tooth contact (B point), shows vertical bone level in mm ( $\mathrm{AB}$ line).

- Vertical bone loss (VBL) was measured by subtracting ( $\mathrm{AB}$ line) at $\mathrm{T} 6$ and $\mathrm{T} 12$ from $(\mathrm{AB}$ line) at T0.

- VBL were calculated at mesial and distal surface of both canines. The data of the mesial and distal surfaces for each tooth was combined. Moreover, the data for the right and left canines for each patient was combined



Fig. (7): A direct digital radiograph of the distal splinted canine abutment with reference lines and points demonstrating the bone height measurements performed by the Scanoralite software. 
Two blinded operators have carried out the evaluation of bone height changes to have precise results.

\section{II- Patient satisfaction (VAS)}

Patient satisfaction was assessed using a questionnaire based on visual analog scale (VAS). Satisfaction after six months follow up period was tested concerning comfort, esthetics, stability, speaking retention, general satisfaction. Patients were requested to mark their answer (amount of satisfaction) on a $100-\mathrm{mm}$ line (with zero indicates not satisfied at all and 100 indicates to completely satisfied). Higher VAS scores showed high satisfaction and lower scores indicated low satisfaction. The mean of the answers (length of the lines from zero to the marks in $\mathrm{mm}$ ) for every question was subjected to statistical analysis.

All dimensions of this instrument were highly associated with the items of general satisfaction (Awad \& Feine, 1998 ${ }^{30}$. The questionnaire was represented to the patients in Arabic (Elsyad, 2016) ${ }^{31}$

\section{Statistical analysis}

For alveolar bone resorption Data were tabulated, coded then analyzed using the computer program SPSS (Statistical package for social science) version 25. Descriptive statistics were represented in the form of Mean \pm Standard deviation (SD) .data was normally distributed as detected by Shapirowilk test. Paired samples t-test was used to compare means of the two different bone resorption values within each group. Independent Samples t-test was used to compare means of resorption values between each two different groups.

To compare patient satisfaction between the 2 groups, MannWhiteny test was utilized. The software package used for data analysis was SPSS ${ }^{\circledR}$ version 25 (SPSS Inc., Chicago, IL, USA). The level of significance was adjusted at $5 \%$

\section{RESULT}

\section{Vertical bone loss (VBL)}

- Columns show mean values of VBL for PEEK framework (group I) and Co-Cr framework (group II) at different observation times are presented in Fig (8).

- Descriptive statistics mean and standard deviation (SD) of VBL at different observation times for both groups are shown in table (1).

- Multiple comparisons between each 2 observation times in the same group showed that VBL significantly increased from T6 to T12 for both groups where $(p=0.038$ and 0.021$)$ for PEEK and $\mathrm{Co}-\mathrm{Cr}$ framework respectively.

- Multiple comparisons between 2 groups at the same observation time revealed that there was a significant difference in VBL between the two groups at $\mathrm{T} 12$ only where $(\mathrm{p}=0.012)$ as $\mathrm{Co}-\mathrm{Cr}$ framework (group II) recorded significant higher VBL at T12 than the PEEK group (group I).

\section{Patient satisfaction parameters}

- Columns show mean values of VAS scores for PEEK and Co-Cr groups at different observation times are presented in Fig (9).

- Comparison of patient satisfaction using VAS between two types of extracoronal attachment RDP frameworks was presented in table (2). PEEK frameworks (group I) showed significant higher satisfaction scores with respect to RPD appearance, comfort and overall satisfaction than Co-Cr framework (group II) where $\mathrm{P}<0.05$. No significant difference between the two types of RPDs frameworks was noted regarding the other aspects of the VAS questionnaire RDP retention, RDP stability, RDP function and speech) where $\mathrm{P}>0.05$. 
TABLE (1): Comparison of mean VBL between different observation times within and between each group.

\begin{tabular}{cccc}
\hline & $\begin{array}{c}\text { T6 } \\
\mathbf{X} \pm \text { SD }\end{array}$ & $\begin{array}{c}\text { T12 } \\
\mathbf{X} \pm \text { SD }\end{array}$ & $\begin{array}{c}\text { T-test } \\
\text { (p value) }\end{array}$ \\
\hline PEEK (group I) & $0.19 \pm 0.03$ & $0.45 \pm 0.05$ & $0.038^{*}$ \\
\hline Co-Cr (group II) & $0.21 \pm 0.04$ & $0.73 \pm 0.11$ & $0.021^{*}$ \\
\hline T-test (p value) & 0.509 & $0.012^{*}$ & \\
\hline
\end{tabular}

$X$ : mean, SD: standard deviation. * $P$ is significant at $5 \%$ level. $(P, T$-test, $p<.05)$

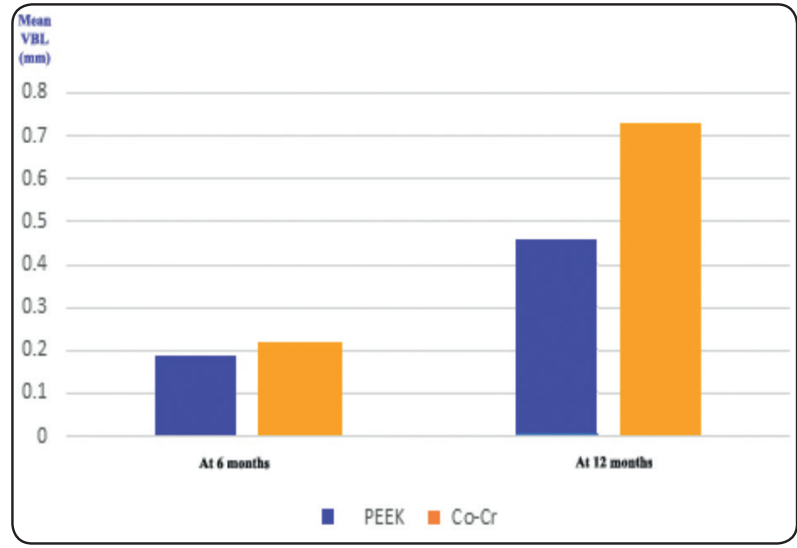

Fig (8): Mean values of VBL for PEEK frameworks (group I) and Co-Cr framework (group II) at different observation times

TABLE (2): Comparison of VAS scores (mm) for both groups of extracoronal attachment RDP framework.

\begin{tabular}{cccccc}
\hline & \multicolumn{2}{c}{ PEEK } & \multicolumn{2}{c}{ Co-Cr } \\
& \multicolumn{2}{c}{ Framework (group I) } & \multicolumn{2}{c}{ Framework (group II) } \\
\cline { 2 - 6 } & Mean & St deviation & Mean & St deviation & P value \\
\hline RDP Retention & 94 & 6.1 & 95 & 6.6 & 0.84 \\
\hline RDP stability & 88 & 8.4 & 86 & 7.8 & 0.94 \\
\hline RDP appearance & 91 & 4.5 & 74 & 9.8 & $0.012^{*}$ \\
\hline RDP comfort & 95 & 7.6 & 82 & 9.7 & $0.023^{*}$ \\
\hline RDP function & 89 & 5.6 & 88 & 5.1 & 0.54 \\
\hline RDP speaking & 94 & 5.5 & 93 & 6.4 & 0.75 \\
\hline RDP overall satisfaction & 93 & 7.7 & 81 & 9.5 & $0.018^{*}$ \\
\hline
\end{tabular}

$X$ : mean, SD: standard deviation. $(P$, Mann Whiteny test $P<.05) * P$ is significant at $5 \%$ level

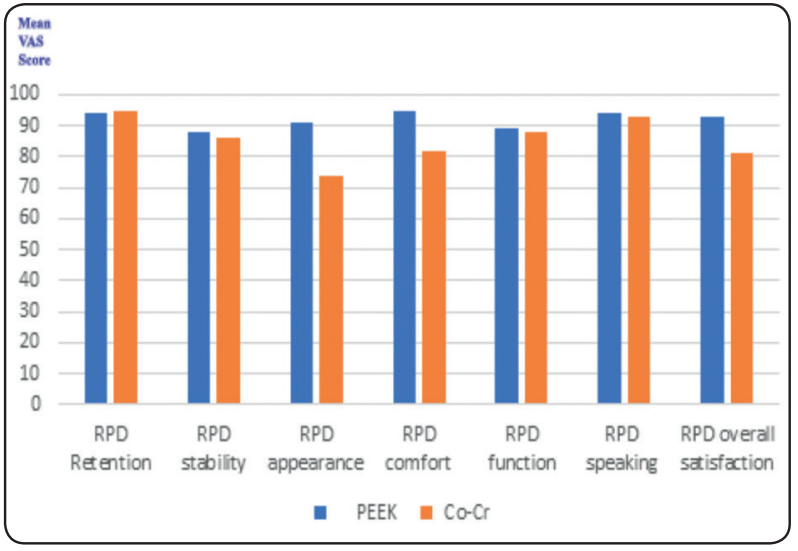

Fig (9). Mean values of VAS scores (mm) for PEEK (group I) and $\mathrm{Co}-\mathrm{Cr}$ (group II) at 6 month after insertion of extracoronal attachment RDP.

\section{DISCUSSION}

In the present study, extracoronal attachment-retained RDPs made with PEEK frameworks resulted in statistically less vertical bone loss around the canine abutments and superior overall patient satisfaction than those made with $\mathrm{Co}-\mathrm{Cr}$ frameworks. Thus, the study hypothesis could be accepted.

The aim of this study was to evaluate the effect of PEEK and Co-Cr as framework material for extra coronal attachment retained RDP on bone height changes to distal abutments and patient satisfaction, as (Mohamed, and Rasha, 2019) ${ }^{32}$ concluded that 
Digitally fabricated RDP frameworks made of PEEK material allows RDPs patients to be more satisfied with their prosthesis than conventional metallic frameworks, thus extending the application of RDP and decreasing patients' rejection to the removable appliances, which will serve to restore more partially edentulous cases with great satisfaction and least complaints.

The distal extension bases are a problem of support because of the deficiency of the distal abutment. Rotation of the distal extension base in a tissue ward direction occurs through function under occlusal force. This problem appears as a result of the variance of the viscoelastic responses among mucosa and the teeth ${ }^{33}$, which results in rotation of the free -end saddle RDP which consequently produces torque and higher liability of abutment damage. This torque should be managed and decreased when designing RDP s particularly with distal extension bases ${ }^{34}$.

As specified by Devan 1952 "Preservation of what is remaining rather than restoration of what is missing" is always the main target in prosthetic dentistry ${ }^{35}$, so the natural abutment should be saved from torquing through function. Resilient extracoronal attachments could be used in cases of distal extension bases permitting for a controlled degree of distal rotation ${ }^{33}$.

Extra-coronal attachments are believed to transfer vertical loads away from the long axis of the abutment. Hence a semi precision "resilient "extracoronal attachment was selected for this study to protect the abutments from unfavorable forces ${ }^{36}$. In the present study, the mandibular six anterior teeth were splinted to make the stress patterns more favorable. Moreover, the use of splinted abutments with milled surfaces aid in fabricating well-constructed dentures. The milled crowns offer the possibility for good support and center the occlusal forces through the long axis of the supporting tooth, allow for a more appropriate load distribution and denture stabilization ${ }^{37}$.
The extracoronal attachment used in this study was OT-strategy which fulfill requirement for creating passively retained extracoronal precision attachment. In addition, the OT strategy which is produced by Rhein is a vertical micro-sized $1.8 \mathrm{~mm}$ castable sphere that is located distally on abutments for RDPs. This type of attachment is characterized by improved shear force strength, improved lateral stability and inhibits rotation of the female cap ${ }^{38}$.

From the results of this study, although the amount of alveolar bone resorption in the distal sides of the distal abutments (canines) were higher than mesial sides in both groups, there was no statistically significant difference in bone loss between mesial and distal aspects.

Regarding the bone height changes around the distal abutments, the result of this study showed increase in the bone loss around distal abutment (canines) of both groups in the first six months (T6) but it was not statistically significant. This could be explained by the inevitable gradual loss of supporting bone that occur after the insertion of any partial denture irrespective of the means of direct retention or attachment design. This explanation is supported by a common prior finding that even well-fabricated partial dentures provoke forces that contribute to gradual bone loss ${ }^{39}$.

This finding could be accredited to the horizontal and lateral forces on the abutment in the distal extension bases which may trigger the interruptiXon of periodontal structures and bone loss ${ }^{40,41}$ as, the crestal bone loss detected in this study is clarified by the fact that bone is constantly renewed by a bone formation and bone resorption. When bone resorption rate surpasses bone formation rate, bone loss happens ${ }^{42}$.

The distal abutments (canines) in both groups showed significant increase in VBL at the second interval period (T12) compared to the first one (T6). This may be due to two main possible reasons .Firstly, the increased ridge resorption that happened 
during the first 6 months of denture insertion may have led to loss of close adaptation of denture base to the ridge and increase fishtail movement of the prosthesis. Secondary, loss of some resiliency of the plastic cap of extracoronal attachment that's to say reduce vertical movement of the denture base under functional loading. Consequently more load were transmitted to the splinted distal canines. The rotation towards the tissue in free end saddle (sinking near at the distal end) increased with bone resorption and the denture in this case acts like extraction forceps ${ }^{43}$.

There was a statistically significant difference in VBL between PEEK (group I) and conventional Co-Cr metallic (group II) extracoronal attachment RDPs after one year from insertion (at T12). The rate of VBL was superior in Co-Cr (group II) than that in PEEK (group I). This could be explained by the modulus of elasticity of PEEK ( $4 \mathrm{GPa}),{ }^{17}$ which is as elastic as bone and can hence decrease stresses transported to the abutment teeth when compared to $\mathrm{Co}-\mathrm{Cr}$ which has a greater modulus of elasticity of about $210 \mathrm{GPa}$ compared to alveolar bone ${ }^{44}$. This justification could be supported by what has been reported by Liebermann et al ${ }^{18}$ who believed that PEEK as a framework material for Kennedy class I RDP cases could be helpful in improving the periodontal health of the abutment teeth, As the elasticity of this material could decrease the distal torque and different stresses on the abutment teeth.

The result of the present study showed significant VBL after 12 months from insertion (PEEK (Group I): 0.45mm \pm 0.05 , Co-Cr (Group II): $0.73 \mathrm{~mm} \pm 0.11)$. These values are comparable to the study of (Ghali, 2017) ${ }^{39}$ who compared three types of attachments to retain RDP in long span mandibular bilateral distally extended cases \{Group I: patients received RDPs retained by extracoronal OT CAP attachment Group II: patients received RDPs retained by telescopic crowns and Group III: patients received RDPs retained by magnetic attachments\}, he found that the mean alveolar bone resorption after 12 months was $0.78 \mathrm{~mm} \pm 0.260 .82 \mathrm{~mm} \pm 0.31$ and $0.63 \mathrm{~mm} \pm 0.22$ for Groups I ,II and III respectively. He concluded that the treatment option by using extracoronal OT CAP attachment showed less stress distribution to the abutment consequently less amount of bone resorption than telescopic attachments.

Results of the present study are comparable to (Sadek, 2019) ${ }^{45}$ who compared four treatment choices for rehabilitation of unilateral distal extended RDP by using OT CAP unilateral attachment (Group 1: full coverage metal crowns with Cobalt-Chromium metal frameworkGroup 2: full coverage metal crowns with BioHpp PEEK framework Group 3: full coverage PEEK crowns with PEEK framework Group 4: full coverage PEEK crowns with metallic frame work). In this in-vitro study, he evaluated the stress dissemination around the splinted abutment teeth and throughout the edentulous ridge. His strain gauge assessment method revealed that, the PEEK-PEEK treatment (group 3) choice showed the most suitable stress dissemination in all parts particularly throughout the abutment teeth.

Results of the present study are also comparable to different researches about the characteristics of PEEK material 19, 21, 23, 24, 46, 47 as they reported that PEEK material has favorable biological and mechanical properties particularly for its flexure behavior which is the chief cause of its advantageous dissemination of stresses.

Since the adaptation of patients' tissues plays a major role in improving the success of the dentures satisfaction of the patients was evaluated six months after denture insertion. ${ }^{39}$ Most patients were greatly satisfied with their dentures with no significant difference for the two groups as regards speaking, stability, retention, and chewing ability. This indicates in general RDPs retained by extracoronal attachments that are well-constructed following biomechanical principles will satisfy the 
"functional" objectives of dentures regardless of the framework material ${ }^{39}$.

However, it is worth mentioning that there was a statistically significant difference in patient satisfaction between PEEK and conventional metallic extracoronal attachment RDPs after six months as regards comfort. The comfort was greater in PEEK (group I) than Co-Cr (group II) and this could be accredited to the weight of the prosthesis that usually has a major influence on patient's comfort. BioHPP PEEK has a minimal specific weight that allows the construction of light prostheses offering high patient satisfaction and comfort through function. In the present study, lingual plate was used instead of a lingual bar, as (Zoidis et. al., 2016) ${ }^{17}$ reported that the PEEK RDP weighed $27.5 \%$ less than its $\mathrm{Cr}-\mathrm{Co}$ antecedent. As, Harb et. al. ${ }^{48}$ also reported that, the small specific weight of PEEK material enables the construction of light prostheses with proper function, which is in agreement with the results of the present study.

Moreover, there was a statistically significant difference in patient satisfaction between the PEEK and conventional metallic (Co-Cr) extracoronal attachment RDPs after six months as regards esthetic. The esthetic was superior in PEEK (group I) than $\mathrm{Co}-\mathrm{Cr}$ (group II) as PEEK accomplishes patient's need of metal free RDPs frameworks ${ }^{25}$.

Regarding the patient overall and general satisfaction, patients' of group I (PEEK frameworks) were generally more satisfied than those with the conventional metallic framework .This is in agreement with (Mohamed \& Rasha , 2019) ${ }^{32}$ who concluded that the computerized manufactured RDP frameworks produced from PEEK material lets RDP patients to be pleased with their prosthesis more than conventional metal frameworks, therefore increasing the application of RDP s and reducing patients' refusal to the removable prosthesis , which will help to rehabilitate more partially edentulous patients with high gratification and minimum complaints.
In addition, the result of present study could be explained by Harb et. al. ${ }^{48}$ and Campbell et. al. ${ }^{25}$ who reported that, digital plans broaden the opportunity of restorative treatments for partial dentures because of enhanced design and manufacture control, recent materials, and enhanced efficacies with suitable fitting that will probably improve outcomes and increase patient experiences.-

However, Zoidis et. al. ${ }^{17}$ recommended that PEEK should be used with attention and still could not be advocated as an alternative to cobalt- chromium frameworks until further and more studies are done its clinical performance.

\section{CONCLUSION}

\section{Within the limitations of this study and within} the specified time frame it could be concluded that:

- Extracoronal attachment retained RDPs with PEEK frameworks resulted in less VBL than those with metallic Co-Cr frameworks

- Patients with PEEK frameworks were more satisfied regarding RDPs appearance, comfort, and overall satisfaction than patients with metallic Co-Cr frameworks

\section{RECOMMENDATION}

1- Further prolonged radiograph prospective longterm evaluation for splinted distal abutments in semi-precision attachment RDP with extracoronal attachment with different framework material may be advised.

2- Periodic monitoring of ridge-base relationship and change polymer matrix every 6 months is mandatory for this type of attachment to assure efficacy of the resiliency of the matrix and close fitness of the denture base to the underlying supporting structure. 


\section{REFERENCES}

1. Hobkirk JA, Watson RM, Searson LJ, Zarb GA: Introducing Dental Implants. Churchill livingstone, Elsevier Science Limited., 2003, 22; 29-42.

2. Reslan MR, Osman E, Segaan L, Rayyan M, Joukhadar C. Comparison between Integrated and Parallel Interlock Designs of an Extracoronal Attachment-retained Distal Extension Removable Partial Dentures: A Clinical Trial. J Int Soc Prev Community Dent. $2021 ; 11: 41$.

3. Gunne HJ. The effect of removable partial dentures on masticatory function and dietary intake. Acta Odontol Stand. 1985; 43:269-278.

4. D. J. Witter et al. The effect of removable partial dentures on the oral function in shortened dental arches. J Oral Rehabil. 1989; 16:27-33.

5. Partielle adjoint. Rev Mens Suisse. Restoration of the partially edentulous mouth-a comparison of overdentures, removable partial dentures, fixed partial dentures and implant treatment. Odontostomatol. 1995; 105:507-511.

6. Phoenix RD, Cagna DR, DeFreest ChF : Stewart's Clinical removable partial prosthodontics (ed 4) Chicago, Berlin, Tokyo, Copenhagen Quintessence Publishing Co, Inc 2008, p 22, 34 355, 363, 273, 376,510.

7. Shillingburg HT, Hobo S, Whitsett LD, Jacobi R, Brackett SE. Fundamentals of fixed prosthodontics. Chicago: Quintessence. 1997; 531-2.

8. Suvarna GS, Nadiger RK, Guttal SS, Shetty O. Prosthetic rehabilitation of hypophosphatasia with precision attachment retained unconventional partial denture: A case report. J Clin Diagn Res. 2014;8:08-10.

9. Shende S, Bodele S, Kubasad G, Deshpande A. Cast partial denture with attachment: Boon to preventive prosthodontics-a case report. Int J Adv Res. 2017;5:290-5.

10. Zajc D, Wichmann M, Reich S, Eitner S. A prefabricated precision attachment: 3 years of experience with the Swiss Mini- SG system. A prospective clinical study. Int J Prosthodont. 2007; 20:432-434.

11. Johannes Schmitt, Manfred Wichmann, PhD, Stephan Eitner, $\mathrm{PhD}$, Jorg Hamel. Five-year clinical follow-up of prefabricated precision attachments: A comparison of uni and bilateral removable dental prostheses. Quintessence Int. 2011; 42:413-418.

12. Den Haan R, Battistuzzi PG, Witter DJ, de Baat C, Creugers NH. (Semi) precision attachments for cast metal frame removable partial dentures. Ned Tijdschr Tandheelkd. 2011;118:93-100.
13. Yeung AL, Lo EC, Chow TW, Clark RK. Oral health status of patients 5-6 years after placement of cobalt-chromium removable partial dentures. J Oral Rehabil. 2000; 27:183-189.

14. El-Charkawi H.G., Zekry K.A. and El-Wakad M.T. Stress analysis of two osseointegrated implants supporting distal extension prosthesis. AL-Azhar Dent J. 1996; 7:347-362.

15. Wöstmann B, Budtz-Jørgensen E, Jepson N, Mushimoto E, Palmqvist S, Sofou A, Öwal B. Indications for removable partial dentures: a literature review. Int. J. Prosthodont.2005; 18, 139- 45 .

16. Monich PR, Berti FV, Porto LM, Henriques B, de Oliveira AP, Fredel MC, Souza J. Physico- chemical and biological assessment of PEEK composites embedding natural amorphous silica fibers for biomedical applications. MAT SCI ENG C-MATER. 2017; 79: 354-362.

17. Zoidis P., Papathanasiou I. and Polyzois G.: The Use of a modified poly ether ether ketone (PEEK) as an alternative framework material for removable dental prostheses. A clinical report. J Prosthet Dent. 2016; 25: 580-584.

18. Liebermann A., Wimmer T., Schmidlin P. R., et al.: Physicomechanical characterization of polyetheretherketone and current esthetic dental CAD/CAM polymers after ag- ing in different storage media. J Prosthet Dent. 2016; 115: 321-328.

19. Stawarczyk B, Beuer F, Wimmer T, Jahn D, Sener B, Roos M, Schmidlin PR. Polyetheretherketone-a suitable material for fixed dental prostheses?. J Biomed Mater Res B Appl Biomater. 2013; 101:1209-16.

20. Costa-Palau et al. Use of Polyetheretherketone in the fabrication of a maxillary obturator prosthesis: A clinical report. J Prosthet Dent. 2014; 112:680-2.

21. Muhsin SA, Wood DJ, Hatton PV, Johnson A, Sereno N. The Effect of Processing Conditions on the Flexural Strength of Polyetheretherketone (PEEK) Used as Innovative Denture Base Material. The 2nd International PEEK Meeting, USA-Washington DC, 23-24th April, 2015.

22. Godara A, Raabe D, Green S. The influence of sterilisation processes on the micromechanical properties of carbon fiber- reinforced PEEK composite for bone implant applications. Acta Biomater. 2007; 3:209-20.

23. Sagomonyants KB, Jarman-Smith ML, Devine JN, Aronow MS, Gronowicz GA. The in vitro response of human osteoblasts to Polyetheretherketone (PEEK) substrates compared to commercially pure titanium .Biomaterials. 2008; 29:1563-72.

24. Schwitalla AD, Spintig T, Kallage I, Müller WD. Flexural behavior of PEEK materials for dental application. Dent Mater. 2015; 31:1377-84. 
25. Campbell SD, Cooper L, Craddock H, Hyde TP, Nattress B, Pavitt SH, Seymour D. Remov- able partial dentures: The clinical need for innovation. J Prosthet Dent. 2017; 118: $273-280$.

26. Koyama S, Sasaki K, Yokoyama M, Sasaki T, Hanawa S. Evaluation of factors affecting the continuing use and patient satisfaction with removable partial dentures over 5 years. J. Prosthodont. Res. 2010; 54: 97-101.

27. Cosme DC, Baldisserotto SM, Fernandes ED, Rivaldo EG, Rosing CK, Shinkai RS. Func- tional evaluation of oral rehabilitation with removable partial dentures after five years. J. Appl. Oral Sci. 2006; 14: 111-116.

28. Fayyad A, Nassouhy N. Comparison between the effect of conventional removable partial dentures and telescopic removable partial dentures on pocket depths and alveolar bone height of abutment teeth. Egypt. Dent. J. 2017;63:1019-26.

29. Langland OE, Langlais RP, Preece .J: Principles of dental imaging. (2nd ed.) Lippincott Williams and Wilkins 2002 p 85-113.

30. Awad MA, Feine JS. Measuring patient satisfaction with mandibular prostheses. Community Dent Oral Epidemiol. 1998;26:400-5.

31. Elsyad, M. A. Patient satisfaction and prosthetic aspects with miniimplants retained mandibular overdentures. A 5year prospective study. Clin. Oral Implants Res. 2016;27,926-933.

32. Mohamed SE, Rasha HG. Digital PEEK framework and patient satisfaction compared to conventional metal framework in removable partial dentures. A clinical trial. Egypt Dent J. 2019; 65:3787-94.

33. Hakim M, Badr AMI. Evaluation of biting force for three different partial denture modalities in bilateral distal extension cases (crossover study). Egypt Dent J .2020; 66:1155-62.

34. Carr AB, McGivney GP and Brown DT. 11th ed. McCraken's removable partial denture prosthodontics. St louis, Baltimore, Toronto: Mosby co,2005 .

35. Devan, M.M., The nature of the partial denture foundation: Suggestions for its preservation. J Prosthet Dent, 1952. 2: 210-218.

36. Igarashi, Y.; Ogata, A.; Kuroiwa, A.; Wang, H.: Stress distribution and abutment tooth mobility of distal-extension removable partial dentures with different retainers: an in vivo study. J. Oral Rehabil. 1999; 26, 111.

37. Pontsa P.: Precision Milling for Partial Denture Design; The Dent-Liner 2008 ;12: 22-34.

38. Rhein83: Attachments and Prefabricated Castable Components Catalog/Technical Manual for Dentists and Dental Technicians. 14 ${ }^{\text {th }}$ edition. Mod. D122 Rev.14 Del 08/02/2021.

39. Ghali RM. Clinical outcome of different types of attachments retaining mandibular kennedy class i partial dentures. Egypt Dent J. 2017; 63:1677-89.

40. Bhathal M, Batra J, Attresh G, Sambyal S. A review on stresses-induced by removable partial dentures. Int J Contemp Dent Med Rev. 2015; 10:1-5.

41. Lee H-E, Wu J-H, Wang C-H, Lan T-H, Du J-K. Biomechanical analysis of distal extension removable partial dentures with different retainers. J. Dent. Sci. 2008; 133-139.

42. Baylink DJ, Wergedal JE, Yamamotos K and Manzke E: Systemic factors in alveolar bone loss. J Prosthet Dent. 1974;31:486-496.

43. Singla SG, Jagmohan LI, Goyal S: Removable partial dentures designing: forces as primary concern. J Indian Prosthodont Soc .2006;6:179-184.

44. Hryniewicz T, Rokicki R, Rokosz K. Co-Cr alloy corrosion behaviour after electropolishing and "magneto electropolishing” treatments. Mater. Lett.. 2008; (17-18):3073-3076.

45. Sadek SA. Comparative study clarifying the usage of PEEK as suitable material to be used as partial denture attachment and framework. Open Access Maced. J. Med. Sci. $2019 ; 7: 1193$.

46. Tekin S, Cangül S, Adıgüzel Ö, Değer Y. Areas for use of PEEK material in dentistry. J. Int. Dent. 2018; 8:84-92.

47. Skirbutis G, Dzingutė A, Masiliūnaitė V, Šulcaitė G, Žilinskas J. A review of PEEK polymer's properties and its use in prosthodontics. Stomatologija. 2017; 19:19-23.

48. Harb I. E., Abdel-Khalek E. A. and Hegazy S. A.: CAD/ CAM constructed polyether ether ketone (PEEK) framework of Kennedy class I removable partial denture: A clinical report. Journal of Prosthodontics. 2018: 1-4. 